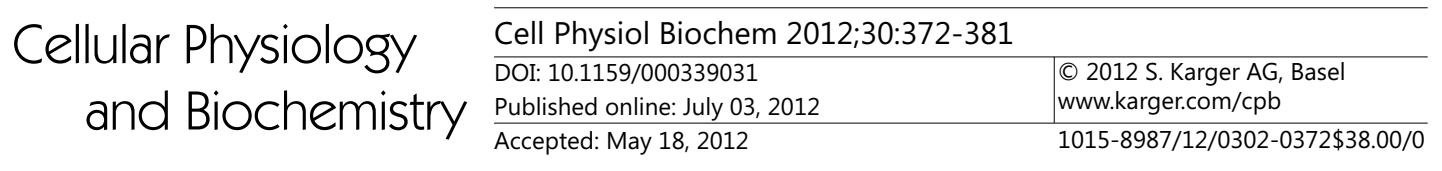

\title{
Upregulation of $\beta 3$-Adrenergic Receptors Contributes to Atrial Structural Remodeling in Rapid Pacing Induced Atrial Fibrillation Canines
}

\author{
Li Sheng $^{1}$ Qiuling Shen ${ }^{1}$ Kan Huang Guangzhong Liu Jing Zhao Wei Xu Yixi \\ Liu Weimin Li Yue Li
}

Department of Cardiology, the First Affiliated Hospital, Harbin Medical University, Harbin, ${ }^{1}$ Authors contributed equally to this work

\section{Key Words}

Atrial fibrillation $\bullet \beta 3$-adrenergic receptor $\bullet$ Oxidative stress $\bullet$ Mitogen-activated protein kinase

- Atrial structural remodeling

\begin{abstract}
Accumulating evidence suggests that the adrenergic receptors (ARs) play an important role in cardiac diseases. The expression of $\beta 3-A R$ has been recently demonstrated in atria, however, its role in atrial structural remodeling of atrial fibrillation (AF) is unclear. Therefore, the present study was designed to investigate the role of $\beta 3-A R$ in atrial structural remodeling in $A F$ and to clarify its possible mechanisms. Twenty-eight dogs were randomly divided into sham, pacing, $\beta 3-A R$ agonist (BRL37344) and $\beta 3-A R$ antagonist (L748337) groups. AF was induced by rapid atrial pacing at 600 beats per minute for 3 weeks and evaluated by determining the ultrastructure and function of atria. The expression of $\beta 3-A R$ and p38 mitogen-activated protein kinase (MAPK) was examined by western blot, immunohistochemistry and real-time RT-PCR. Additionally, the extent of oxidative stress was tested. We found the atrial enlargement and dysfunction in pacing group. Moreover, atrial interstitial fibrosis, apoptosis and oxidative stress were increased and the levels of $\beta 3-A R$ and phosphorylated p38 MAPK were increased after pacing. Activation of $\beta 3$-AR exacerbated the pathologic changes and oxidative stress, which were effectively inhibited by L748337. We concluded that $\beta 3$-AR was upregulated in paced atria, which contributed to oxidative stress and exacerbated atrial structural remodeling by regulating $\mathrm{p} 38 \mathrm{MAPK}$. Our study provides novel insights into the pharmacological role of $\beta 3-A R$ in AF.
\end{abstract}




\section{Cellular Physiology and Biochemistry}

Cell Physiol Biochem 2012;30:372-381

\begin{tabular}{l|l}
\hline DOI: $10.1159 / 000339031$ & $\begin{array}{l}\text { C) 2012 S. Karger AG, Basel } \\
\text { www.karger.com/cpb }\end{array}$ \\
Published online: July 03, 2012 & w
\end{tabular}

\section{Introduction}

Atrial fibrillation (AF) is one of the most common arrhythmia in clinical practice, which is associated with pronounced morbidity and mortality [1]. Previous studies have shown that both electrical and structural remodeling occurred in the atria of AF patients and animals [2]. Atrial structural remodeling primarily impedes propagation and decreases conduction velocity, and is considered to be the major contributor to the persistence of AF [3]. Recently, it has been suggested that the apoptosis and interstitial fibrosis in atria may lead to the development of atrial structural remodeling, which may further induce atrial conduction impairment and AF vulnerability increment [4]. However, the pathogenesis underlying atrial structural remodeling remains poorly understood.

The $\beta$-adrenergic receptors ( $\beta$-ARs) system, including $\beta 1$-, $\beta 2$ - and $\beta 3$-ARs subtypes, is involved in a variety of cardiovascular diseases [5]. Specifically, $\beta 3$-AR is different from other subtypes in several aspects, such as molecular structure and affinity for adrenergic ligands [6]. Its critical role in regulation of catecholamine has now been demonstrated to be pivotal for many organs [7]. Additionally, activation of $\beta 3$-AR could decrease myocardial contractility and reduce the occurrence of ventricular tachycardia [8-10]. Recently, many studies have focused on the potential role of atrial $\beta 3$-AR in cardiovascular diseases, such as heart failure and ischemic cardiomyopathy $[11,12]$. Nevertheless, its role in the pathologic process of AF has not been well elucidated.

It is well recognized that oxidative stress is an important contributor for cardiac remodeling [13]. Generation of reactive oxygen species (ROS) could modulate cellular and extra-cellular structure and function in the heart. It has been uncovered that inhibition of ROS could effectively prevent the atrial remodeling in AF $[14,15]$. On the other hand, mitogen-activated protein kinase (MAPK) family participates in the process of atrial structural remodeling $[16,17]$. However, the association among $\beta 3-A R$, oxidative stress and MAPK signaling cascade in atrial structural remodeling remains unknown. Therefore, this study was undertaken to investigate the potential role and possible mechanisms of $\beta 3$-ARs in atrial structural remodeling of AF.

\section{Materials and Methods}

\section{Animal models}

Twenty-eight healthy dogs (15 22 kg) from Experimental Animal Center of the First Affiliated Hospital of Harbin Medical University (Harbin, China) were used in this study. All experimental procedures were in accordance with the regulations of the Experimental Animal Ethic Committee of Harbin Medical University and conformed to the Guide for the Care and Use of Laboratory Animals of the National Institutes of Health (Publication No. 85-23, revised 1996). All dogs were randomly divided into four groups: sham, pacing, $\beta 3-$ ARs agonist (BRL37344, Sigma Co., B169) and $\beta 3$-ARs antagonist (L748337, Santa cruz, sc-204044) groups. After anesthesia, one thin silicon lead was implanted in the free wall of right atrial appendage and connected to a pacemaker (Fudan University, Shanghai, China) with a frequency of 600 beats per minute (bpm) [18, 19]. The dogs were treated with penicilin during the operation. After one week recovery, atrial pacing was started in all dogs and last for 3 weeks except the sham group. Dogs in the $\beta 3$-AR agonist group were given BRL37344 $1.5 \mu \mathrm{g} \cdot \mathrm{kg}^{-1} \cdot \mathrm{h}^{-1}$ subcutaneously and continuously for 3 weeks by the osmotic pump [10]. The dogs in $\beta 3$-ARs antagonist group were infused with $\mathrm{L} 7483372 \mu \mathrm{g} \cdot \mathrm{kg}^{-1} \cdot \mathrm{h}^{-1}$ by osmotic pump subcutaneously for 3 weeks $[9,10]$.

\section{Histology}

The hearts were removed immediately after all dogs were anesthetized. Then left and right atria were quickly removed and cut into 3 (upper, middle, lower) sections. Each section was divided equally into 4 pieces. Each of pieces from each section was randomly chosen to perform electron microscopy. One part was paraffin-embedded for Masson trichrome staining, apoptosis and immunohistochemistry analysis. The remaining parts were quickly frozen in liquid nitrogen and maintained at $-80^{\circ} \mathrm{C}$ until use for mRNA, protein and oxidative stress analysis. 


\section{Cellular Physiology and Biochemistry}

\begin{tabular}{|c|c|}
\hline Cell Physiol Biochem 20 & \\
\hline $\begin{array}{l}\text { DOI: } 10.1159 / 000339031 \\
\text { Published online July 03.2012 }\end{array}$ & $\begin{array}{l}\text { (c) } 2012 \text { S. Karger AG, Basel } \\
\text { www.karger.com/cpb }\end{array}$ \\
\hline
\end{tabular}

Sheng/Shen/Huang et al.: Role of $\beta 3$-ARs in Atrial Structural Remodeling

Echocardiography

Transthoracic and transesophageal echocardiography were performed before operation and heart removal (Philips 7500, Washington, USA). Maximum left atrium volume $\left(\mathrm{LAV}_{\max }\right)$, minimal left atrium volume $\left(\mathrm{LAV}_{\min }\right)$, maximum left atrial appendage volume $\left(\mathrm{LAAV}_{\max }\right)$ and minimum left atrial appendage volume $\left(L A A V_{\text {min }}\right.$ ) were measured before and after pacing. $L A V_{\max }$ and $L A A V_{\text {max }}$ were recorded at $L V$ end-systole while $\mathrm{LAV}_{\text {min }}$ and $\mathrm{LAAV}_{\min }$ were recorded at $\mathrm{LV}$ end-diastole. LA ejection fraction (LAEF) was calculated as $\left(\mathrm{LAV}_{\max }-\mathrm{LAV}_{\min }\right) / \mathrm{LAV}_{\max } \times 100 \%$ and LAA ejection fraction (LAAEF) was calculated as $\left(\mathrm{LAAV}_{\max }-\mathrm{LAAV}_{\min }\right) /$ $\mathrm{LAAV}_{\max } \times 100 \%[20]$.

\section{Electron microscopy}

Atria were fixed in $2 \%$ glutaraldehyde at $4^{\circ} \mathrm{C}$, in $0.1 \mathrm{~mol} / \mathrm{L}$ cacodylate buffer ( $\left.\mathrm{pH} 7.4\right)$. Then, the tissues were prepared in $1 \%$ osmium tetroxide, supplemented with $1.5 \% \mathrm{~K}_{4} \mathrm{Fe}(\mathrm{CN})_{6}$ in cacodylate buffer at $4^{\circ} \mathrm{C}$ $(\mathrm{pH}$ 7.4). After dehydration in ethanol, they were cut into ultrathin sections $(50 \sim 100 \mathrm{~nm})$, stained by uranyl acetate and lead citrate, then rinsed after differentiation to be dry for observation. The sections were detected in the electron microscope (JEM-7650, Hitatchi, Japan) by two professionals who were unaware of the treatment [20].

\section{TUNEL assay}

Atria were fixed in $10 \%$ paraformaldehyde, embedded in paraffin and sectioned at $5 \mathrm{~mm}$. The samples were then processed for TdT-mediated dUTP nick end labelling (TUNEL) assay. The in situ Cell Death Detection Kit was used according to the manufacturer's instructions (Roche Applied Science). Apoptosis positive nucleus was stained with dark brown. Apoptosis index (AI, \%) was calculated as apoptotic cell numbers/total cell numbers $\times 100 \%[20]$.

\section{Masson trichrome staining}

Left and right atrial free wall were cut into small pieces and immersed in 10\% phosphate-buffered formalin for $24 \mathrm{~h}$, and then they were deparaffined and stained with Masson's trichrome according to the manufacturer's instructions. The collagen fibers were marked with blue, while the cardiomyocytes were marked with red. Digital medical image analysis system was used for measurement of collagen volume fraction (CVF) in each field (BX60, Olympus, Japan) [3].

\section{Western blot}

Left and right atria were homogenized, and protein was extracted and quantified. After SDSpolyacrylamide gel electrophoresis, the protein was transferred into nitrocellulose membranes (HaiGene, China). Then, the membranes were incubated overnight with rabbit anti- $\beta 3$-ARs antibody (1:500, Abcam, ab76249), anti-p38 MAPK antibody (1:500, Abcam, ab32142), anti-phosphorylated p38 MAPK antibody (1:500, Abcam, ab47363) and anti- $\beta$-actin antibody (HaiGene, M1501). Then, membranes were incubated with secondary horseradish peroxidase-conjugated antibody (1:5000, HaiGene, China). The films were exposed with enhanced ECL buffer. The density of bands was quantified by ImagePro software [3].

\section{Immunohistochemistry}

Atrial sections were cut into $6 \mu \mathrm{m}$ thick slices. They were washed and blocked, and then incubated with polyclonal rabbit phosphorylated anti-p38 MAPK (1:100, Abcam, ab47363), anti-ERK1/2 (1:200, Abcam, ab50011).

After washing with PBS, the sections were incubated with peroxidase conjugated goat anti-rabbit IgG (Boster Biotechnology Co., China) for 20 min. Peroxidase activity was detected using diaminobenzidine (DAB). After staining, sections were rinsed with water, counterstained with haematoxylin and mounted with glycerol gelatin [20].

\section{Real-time RT-PCR}

Total RNA was isolated from atrial by Trizol methods. Total RNA was reverse-transcribed using a reverse transcription kit. The mRNA levels for $\beta 3$-ARs were quantified by SYBR Green incorporation on ABI 7500 Real Time PCR system (Applied Biosystems, USA). $\beta 3$-ARs was amplified from dog atrial cDNA using the forward primer (5'-GTG GGC ACC TTC ACT CTC TG-3') and reverse primer (5'-GGC AGT AGA TGA GCG GG TTG-3'), glyceraldehyde-3-phosphate dehydrogenase (GAPDH) was employed as the internal control, the 


\section{Cellular Physiology $\quad$ Cell Physiol Biochem 2012;30:372-381

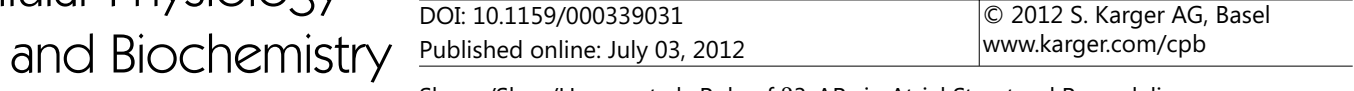 \\ Sheng/Shen/Huang et al.: Role of $\beta 3$-ARs in Atrial Structural Remodeling}

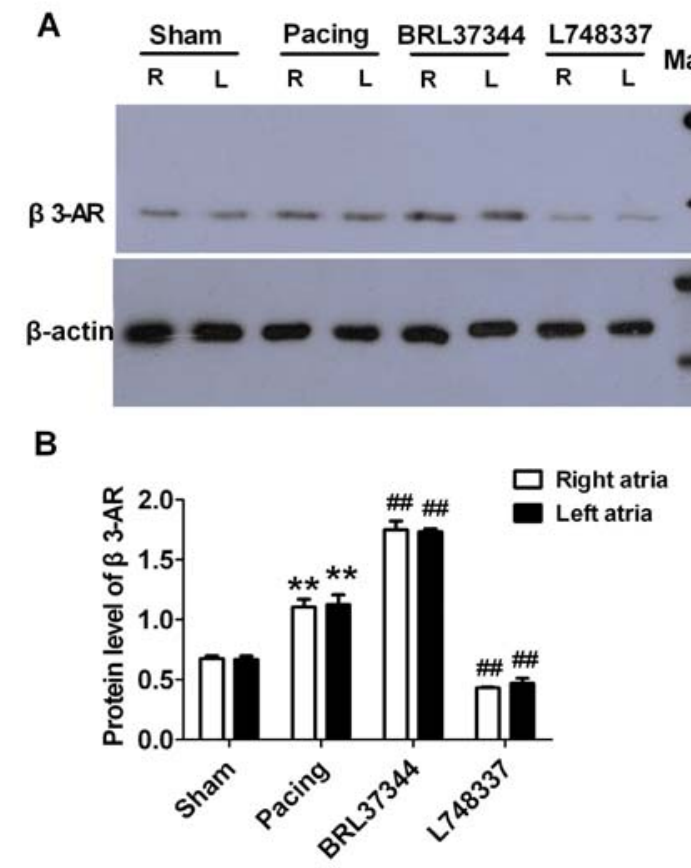

Fig. 1. mRNA and protein expression of $\beta 3$-ARs. ${ }^{* *} P<0.01$ vs. sham group; $\# \# P<0.01$ vs. pacing group. There was no difference between right and left atria in each group $(n=7$ in each group).

forward primer of which was 5'-AGG TAG TGA AGC AGG CAT CG-3' and reverse primer was 5'-GAA GGT GGA AGA GTG GGT GTC-3'.

\section{Oxidative stress determination}

Frozen blocks were measured according to the ratio of mass and volume of physiologic saline preparation into $10 \%$ tissue homogenate, and centrifuged at $1610 \mathrm{~g}$ for $10 \mathrm{~min}$ according to manufacturer's instructions (Coomassie brilliant blue protein assay kit). Protein concentrations were measured by BioRad protein assay kit according to the manufacturer's instructions (Jiancheng Biological Technical Institute, Nanjing, China). Then malonaldehyde (MDA), lactate dehydrogenase (LDH) and glutathione peroxidase (GSH-PX) were measured under different wavelength (532 nm, $450 \mathrm{~nm}$ and $412 \mathrm{~nm}$, respectively) by spectrophotometer colorimetry [4].

\section{Statistical analysis}

SPSS 11.5 software was used. Quantitative data were presented as mean \pm SD. Multiple comparisons were carried out among the groups using one-way analyses of variance (ANOVA) followed by Dunnett's t-test. Qualitative data were analyzed with the chi-square test. $P<0.05$ was considered to be statistically significant.

\section{Results}

$m R N A$ and protein expression of $\beta 3-A R s$

The mRNA level of $\beta 3$-ARs was higher in pacing group in both right and left atria than the sham group. In addition, the mRNA level of $\beta 3$-ARs was increased by $\beta 3$-ARs agonist and decreased by $\beta 3$-ARs antagonist (Fig. 1C). The protein expression of $\beta 3$-ARs was significantly increased in the pacing group compared with the sham group in both right and left atria. 


\section{Cellular Physiology Cell Physiol Biochem 2012;30:372-381 \begin{tabular}{ll|l} 
and Biochemistry & $\begin{array}{l}\text { DOI: 10.1159/000339031 } \\
\text { Published online: July 03, 2012 }\end{array}$ & $\begin{array}{l}\text { O 2012 S. Karger AG, Basel } \\
\text { www.karger.com/cpb }\end{array}$ \\
\cline { 2 - 2 } & Swar.
\end{tabular} \\ Sheng/Shen/Huang et al.: Role of $\beta 3$-ARs in Atrial Structural Remodeling}

\begin{tabular}{|c|c|c|c|c|c|c|}
\hline & $\mathrm{LAV}_{\max }(\mathrm{mL})$ & $\mathrm{LAV}_{\min }(\mathrm{mL})$ & LAEF (\%) & $\mathrm{LAAV}_{\max }(\mathrm{mL})$ & $\mathrm{LAAV}_{\min }(\mathrm{mL})$ & LAAEF (\%) \\
\hline \multicolumn{7}{|l|}{ Sham group } \\
\hline Baseline & $12.89 \pm 1.69$ & $6.26 \pm 1.02$ & $51.27 \pm 6.36$ & $1.84 \pm 0.26$ & $0.87 \pm 0.14$ & $52.50 \pm 5.50$ \\
\hline 4 weeks post-operation & $12.54 \pm 1.75$ & $6.40 \pm 0.90$ & $48.40 \pm 8.47$ & $1.97 \pm 0.34$ & $0.93 \pm 0.16$ & $52.34 \pm 7.12$ \\
\hline \multicolumn{7}{|l|}{ Pacing group } \\
\hline Baseline & $13.13 \pm 1.45$ & $6.37 \pm 1.03$ & $51.19 \pm 7.67$ & $1.94 \pm 0.11$ & $0.90 \pm 0.12$ & $53.40 \pm 7.54$ \\
\hline 3 weeks after pacing & $23.46 \pm 2.26 \% * *$ & $14.67 \pm 1.24 * * *$ & $34.32 \pm 3.29 * * *$ & $3.01 \pm 0.35 \div * *$ & $1.91 \pm 0.23 *^{* *}$ & $36.49 \pm 1.91 * * *$ \\
\hline \multicolumn{7}{|l|}{ BRL37344 group } \\
\hline Baseline & $12.91 \pm 1.49$ & $6.33 \pm 0.92$ & $50.96 \pm 5.30$ & $1.89 \pm 0.31$ & $0.83 \pm 0.18$ & $55.85 \pm 7.04$ \\
\hline 3 weeks after pacing & $26.34 \pm 1.60$ t册 & $18.53 \pm 0.84 \ddagger$ & $29.47 \pm 4.94$ 市\# & $3.76 \pm 0.40 \div \#$ & $2.61 \pm 0.24 \dagger \#$ & $30.31 \pm 1.60 \%$ \\
\hline \multicolumn{7}{|l|}{ L748337 group } \\
\hline Baseline & $13.47 \pm 1.13$ & $6.46 \pm 0.76$ & $52.04 \pm 4.49$ & $1.79 \pm 0.34$ & $0.81 \pm 0.15$ & $53.69 \pm 7.16$ \\
\hline 3 weeks after pacing & $17.66 \pm 2.57 \ddagger$ & $9.73 \pm 1.17 \mathbf{t} \#$ & $44.35 \pm 7.56 \dagger \#$ & $2.24 \pm 0.22 \ddagger \# \#$ & 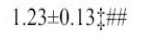 & $45.15 \pm 3.06 \leftrightarrows \#$ \\
\hline
\end{tabular}

Table 1. Atrial structure and function of rapid pacing induced atrial fibrillation canines. $\dagger P<0.05, \ddagger P<$ 0.01 , vs. baseline; ${ }^{*} P<0.05,{ }^{* *} P<0.01$ vs. sham group; $\# P<0.05, \# \# P<0.01$, vs. pacing group $(\mathrm{n}=7$ in each group).

Fig. 2. Effect of $\beta 3$ adrenergic receptors $(\beta 3$ ARs) on ultrastructure of atria in atrial fibrillation (AF) canines. Atrial myocytes from sham dogs had regular sarcomere organization, normal nuclei and uniformly sized mitochondria (A). Samples of atrial tissue taken from pacing dogs showed partial disintegration of myofilaments, replaced by mitochondria and fibrous tissues. Nuclei showed slightly atrophic

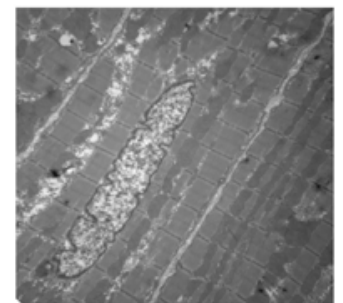

A

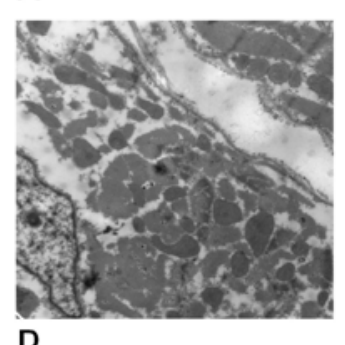

D

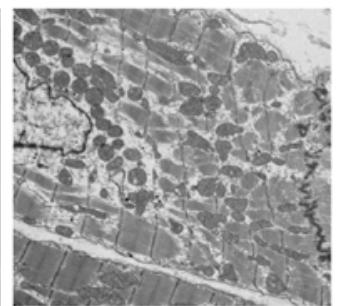

B

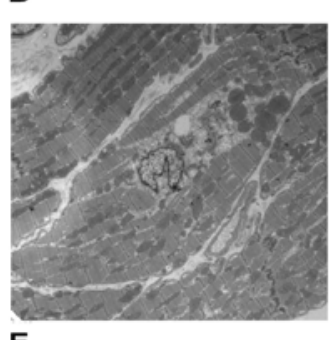

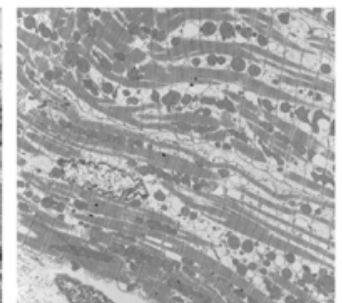

C

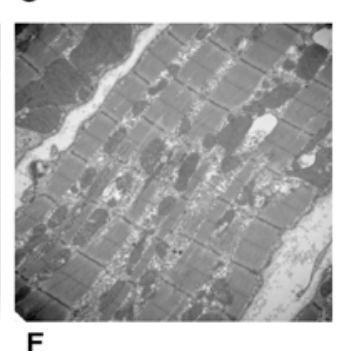

(B). After treatment with BRL37344, most of the myofilaments were disintegrated, replaced by mitochondria and fibrous tissues, and nuclei showed atrophic (C, D), even karyopyknosis (E). In contrast, these chronic pacing-induced ultrastructural changes were markedly attenuated by treatment with L748337, showing slight disintegration of myofilaments and changes of mitochondria (F). (Magnification A, B and F $\times 10000, C$, $\mathrm{E} \times 5000, \mathrm{D} \times 15000, \mathrm{n}=7$ in each group).

Moreover, it was higher in $\beta 3$-ARs agonist group, which was inhibited by $\beta 3$-ARs antagonist (Fig. 1A, B). However, there was no significance between right and left atria in each group (Fig. 1B).

\section{Atrial structure, function}

Echocardiography (Table 1) showed a significant increase in $\mathrm{LAV}_{\text {max }^{\prime}} \mathrm{LAV}_{\text {min }^{\prime}} \mathrm{LAAV}_{\text {max }}$ and $\mathrm{LAAV}_{\text {min }}$, whereas a marked decrease in LAEF and LAAEF in pacing group. Atrial structure and function were further exacerbated in the $\beta 3$-AR agonist group than the pacing group, which was restored in $\beta 3$-ARs antagonist groups. 


\section{Cellular Physiology Cell Physiol Biochem 2012;30:372-381 \begin{tabular}{ll|l} 
and BiOChemistry & $\begin{array}{l}\text { DOI: 10.1159/000339031 } \\
\text { Published online: July 03, } 2012\end{array}$ & $\begin{array}{l}\text { C 2012 S. Karger AG, Basel } \\
\text { www.karger.com/cpb }\end{array}$ \\
\cline { 2 - 3 } & Sheng/Shen/Huang et al: Role of $\beta 3$-ARs in Atrial Structural Remodeling
\end{tabular}}

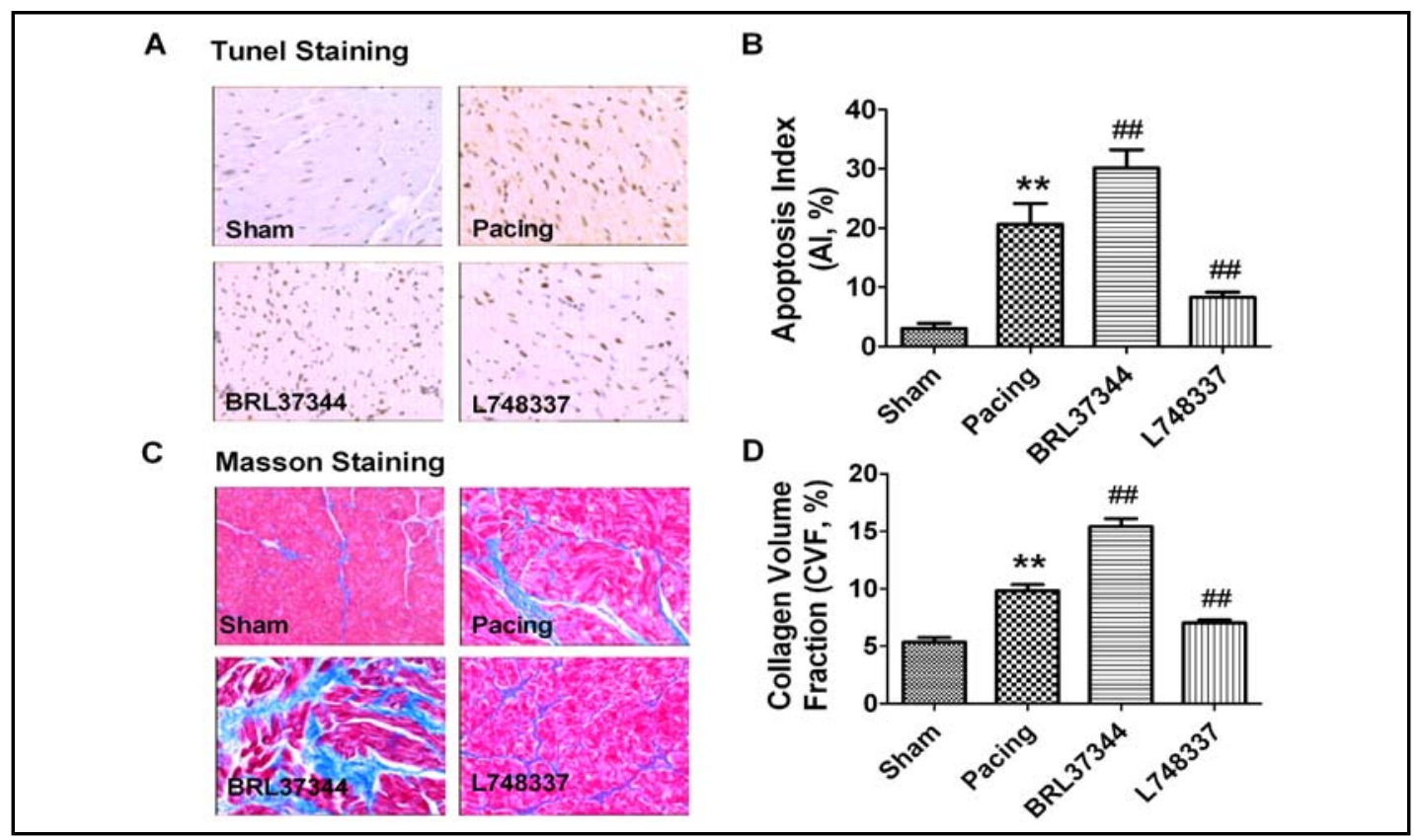

Fig. 3. Effect of $\beta 3$-ARs on atrial apoptosis (A, B) and fibrosis (C, D) in AF canines. ${ }^{* *} P<0.01$ vs. sham group; $\# \# P<0.01$ vs. pacing group (The magnification is $\times 200, n=7$ in each group).

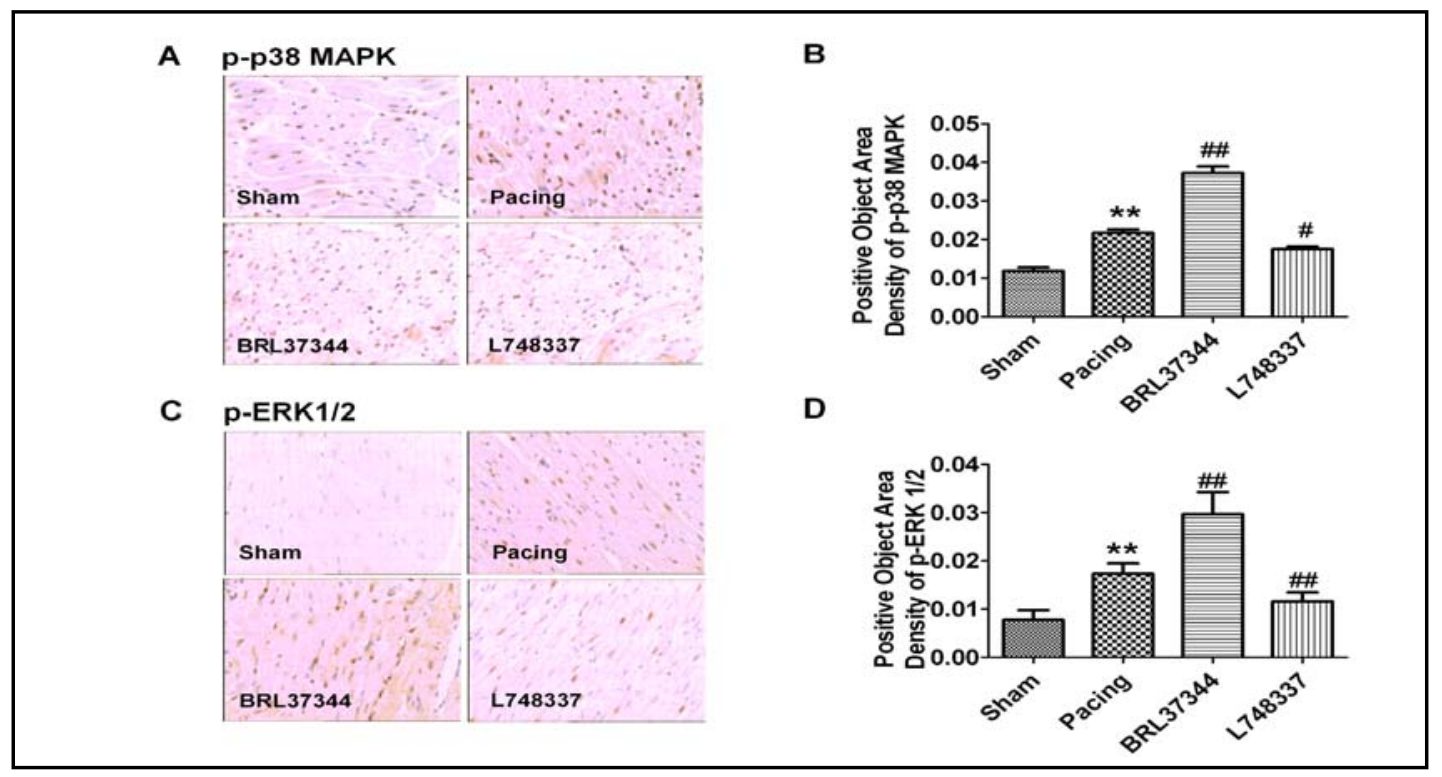

Fig. 4. Immunohistochemistry analysis of p-p38 MAPK (A, B) and p-ERK1/2 (C, D). ${ }^{* *} P<0.01$ vs. sham group; \#\# $P<0.01$ vs. pacing group (The magnification is $\times 200, \mathrm{n}=7$ in each group).

\section{Apoptosis and interstitial fibrosis}

Fig. 2A showed that atrial myocytes displayed regular sarcomere organization, normal nuclei and mitochondria with uniform size in the sham group. However, partial disintegration of myofilaments was replaced by mitochondria, fibrous tissues and slightly atrophic nuclei in the pacing group (Fig. 2B). After treated with BRL37344, most of the myofilaments were disintegrated, and replaced by mitochondria and fibrous tissues, and nuclei showed atrophic even karyopyknosis (Fig. 2C-E). In contrast, these ultrastructural changes were markedly attenuated by L748337, showing slight disintegration of myofilaments and changes of mitochondria (Fig. 2F). 


\begin{tabular}{|c|c|c|}
\hline Cellular Ph & Cell Physiol Biochem 2012;30:372-381 & \\
\hline and Biochemistry & $\begin{array}{l}\text { DOI: 10.1159/000339031 } \\
\text { Published olline: July 03, } 2012\end{array}$ & $\begin{array}{l}\text { (c) } 2012 \text { S. Karger AG, Basel } \\
\text { www.karger.com/cpb }\end{array}$ \\
\hline
\end{tabular}

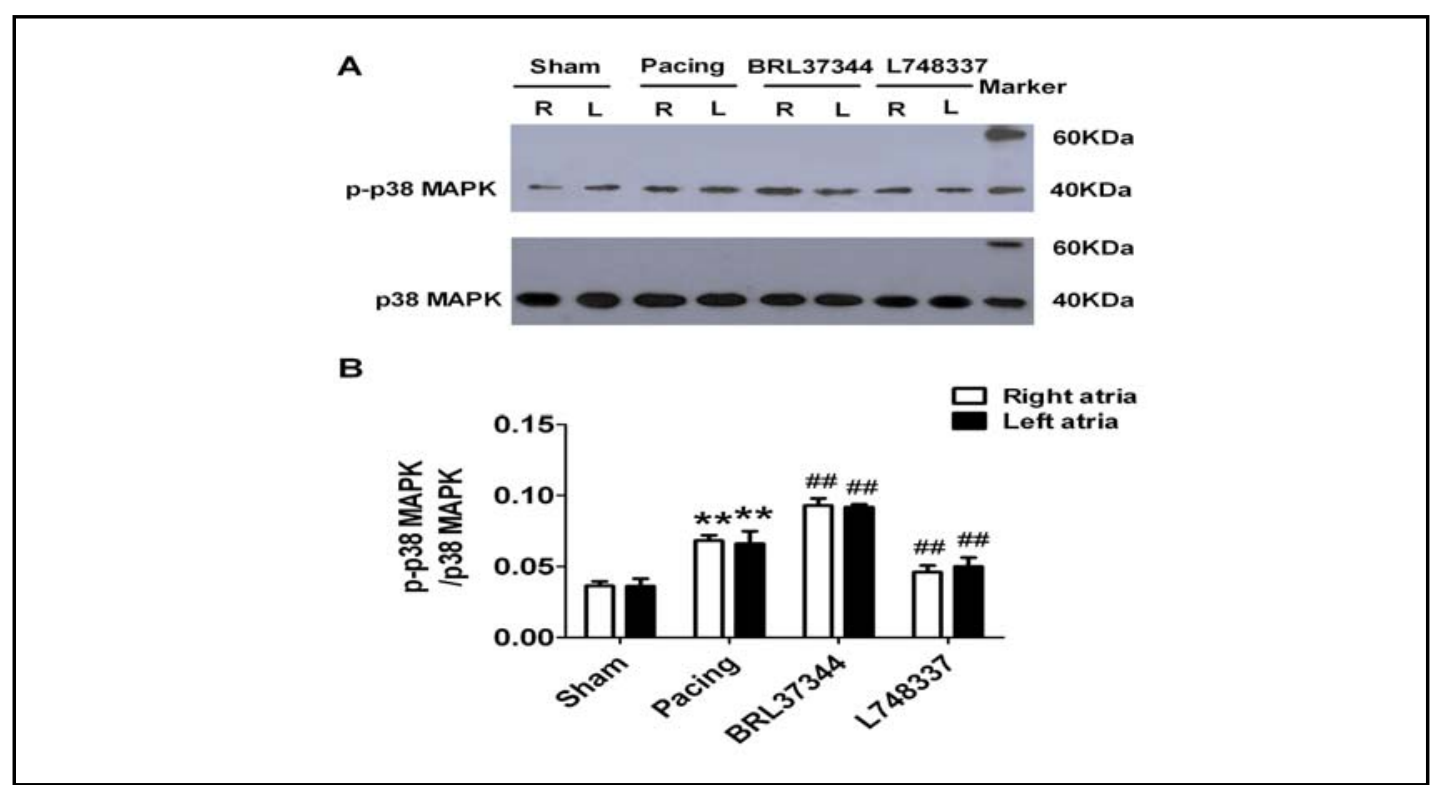

Fig. 5. Protein expression of p-p38 MAPK. ${ }^{* *} P<0.01$ vs. sham group; $\# \# P<0.01$ vs. pacing group. There was no difference between right and left atria in each group ( $n=7$ in each group).

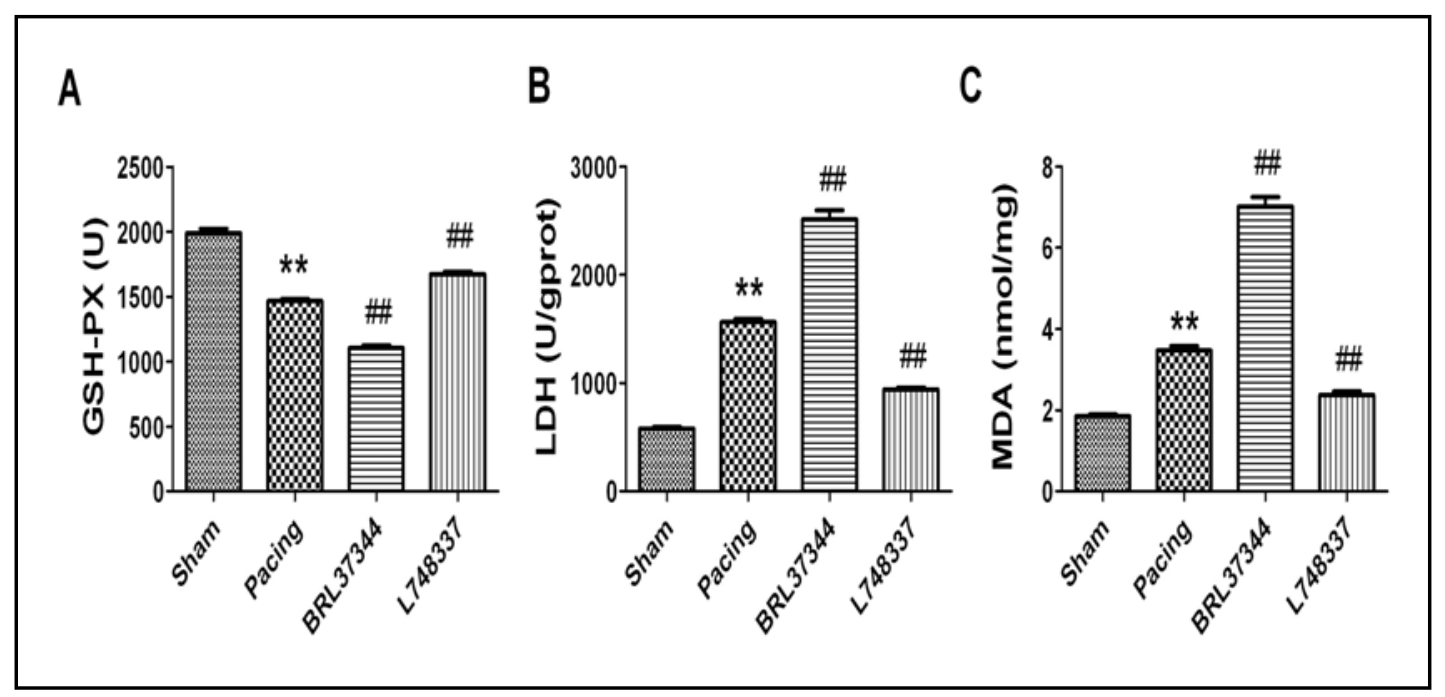

Fig. 6. Effect of $\beta 3$-ARs on GSH-PX (A), LDH (B) and MDA (C) in AF canines. ${ }^{*} P<0.01$ vs. sham group; \#\#P $<0.01$ vs. pacing group ( $\mathrm{n}=7$ in each group).

TUNEL-positive cells showed shrunken cytoplasm, apoptotic bodies, pycnotic nuclei and stained brown. The percentage of TUNEL-positive cells was dramatically increased in the pacing group, further increased in $\beta 3$-ARs agonist groups and dramatically decreased in the $\beta 3$-ARs antagonist groups (Fig. 3A, B). Collagen fibers stained blue with Masson's trichrome stain (Fig. 3C, D). CVF was significantly higher in pacing group than that in sham group. After treated with $\beta 3$-ARs agonist, CVF was further increased compared with the pacing group, whereas significantly reduced in the $\beta 3$-ARs antagonist group.

\section{Expression of phosphorylated $p 38$ MAPK and phosphorylated ERK}

Immunohistochemistry analysis showed the expression of phosphorylated p38 MAPK and phosphorylated ERK (Fig. 4). The expressions of phosphorylated p38 MAPK and phosphorylated ERK in the pacing group was obviously increased. They were increased after treatment with $\beta 3$-ARs agonist compared with the pacing group. In contrast, the levels were dramatically decreased after $\beta 3$-ARs antagonist treatment (Fig. 4). 


\section{Cellular Physiology and Biochemistry}

Cell Physiol Biochem 2012;30:372-381

\begin{tabular}{l|l}
\hline DOI: $10.1159 / 000339031$ & $\begin{array}{l}\text { C) 2012 S. Karger AG, Basel } \\
\text { www.karger.com/cpb }\end{array}$ \\
Published online: July 03, 2012 & wat
\end{tabular}

Sheng/Shen/Huang et al.: Role of $\beta 3$-ARs in Atrial Structural Remodeling

\section{Protein expression of $p 38 M A P K$}

The phosphorylated level of p38 MAPK was significantly enhanced in the pacing group in both right and left atria compared with the sham group. Similarly, the phosphorylated level of p38 MAPK increased significantly in the $\beta 3$-ARs agonist group compared with the pacing group, which was reversed by the antagonist. There were no significant differences between right and left atria in expression of phosphorylated p38 MAPK (Fig. 5A, B).

\section{Oxidative stress}

Figure 6 showed a significant increase of LDH and MDA and decrease of GSH-PX in the pacing group compared with sham group. After treatment with $\beta 3$-ARs agonist, LDH and MDA were higher while GSH-PX was lower than the pacing group. These alterations were abolished by antagonist of $\beta 3$-ARs.

\section{Discussion}

The main finding of the present study was that activation of $\beta 3$-ARs could promote the atrial structural remodeling in AF, at least partially by regulating p38 MAPK and oxidative stress. The impairment of $\beta 3$-ARs on atrial structural remodeling was exacerbated by its angonist BRL37344 and was reversed by its antagonist L748337. These findings provide a new insight into the pathophysiologic role of $\beta 3$-ARs in atrial structural remodeling in $\mathrm{AF}$.

Many recent studies indicate that oxidative stress injury plays an important role in AF structural remodeling [1, 3]. For example, Mihm et al. [13] found that atrial appendages of patients with AF undergoing the Maze procedure exhibited higher levels of oxidative stress markers, 3-nitrotyrosine and protein carbonyls, than patients with sinus rhythm undergoing cardiac surgery. Kim et al. [21] proved that ROS generation increased, while expression of antioxidant factors decreased in isolated atrial myocytes from human right atrial appendages suffering from AF. Similarily, we found that the levels of LDH and MDA increased in atrium and GSH-PX decreased in rapid atrial pacing atria. Meanwhile, other studies also found that oxidative stress in AF may participate in atrial structural remodeling process [13-15]. Excessive ROS induced by oxidative stress injury can directly cause myocardial cell damage and fibrosis, thus inhibition of ROS can prevent the atrial remodeling.

MAPK family is a group of important kinases that links to multiple signal pathways of atrial structural remodeling [17]. NADPH oxidase is one of the most important producers of ROS, which mediates signal pathway associated with MAPK [22]. It could be activated by ROS in both cardiomyocytes and fibroblasts [22]. MAPK signal pathways can cause fibroblast over-proliferation, expression of pro-fibrotic genes increment and an imbalance between matrix metalloproteinase (MMP) and tissue inhibitor of metalloproteinase (TIMP) [17]. Activations of p38 MAPK triggers the activation of apoptotic pathways through oxidative stress, such as activation of Bax, caspases and release of cytochrome c [23, 24]. Our results showed that oxidative stress, apoptosis and fibrosis were severer after rapid atrial pacing. The function of atria was decreased after pacing for 3 weeks. Moreover, the phosphorylated levels of p38 MAPK was higher in AF. Thus, our results unraveled a potential relationship between oxidative stress and p38 MAPK in pathophysiologial changes of AF.

A growing body of evidence has demonstrated that $\beta$-ARs system plays an important role in the regulation of cardiovascular function [7]. Contrary to $\beta 1$ - and $\beta 2$-ARs, $\beta 3$ ARs mediate a negative inotropic effect in human ventricular muscle. Moniotte et al [11] analyzed left ventricular samples from 29 failing hearts and 25 non-failing explanted hearts, and found that $\beta 3$-ARs protein expression showed up to 2-3 fold increase in failing hearts compared with non-failing hearts. As a result, it is implied that $\beta 3$-ARs might contribute to the functional degradation in human failing hearts. However, the influence of $\beta 3$-ARs on susceptibility to arrhythmias is largely unknown. Yu et al [25] reported that activation of $\beta 3$ ARs promoted the atrial electrical remodeling process by altering the balance of ion channels in atrial myocytes in acute rapid atrial arrhythmia. Short-term pacing model was used to investigate the AF electrical remodeling induced by activation of $\beta 3$-ARs. In constrast, long- 


\section{Cellular Physiology and Biochemistry}

\begin{tabular}{|c|c|}
\hline \multicolumn{2}{|c|}{ Cell Physiol Biochem 2012;30:372-381 } \\
\hline $\begin{array}{l}\text { DOI: } 10.1159 / 000339031 \\
\text { Published online: July 03, } 2012\end{array}$ & $\begin{array}{l}\text { (c) } 2012 \text { S. Karger AG, Basel } \\
\text { www.karger.com/cpb }\end{array}$ \\
\hline
\end{tabular}

term pacing model was established to explore the relationship between $\beta 3$-ARs and atrial structural remodeling in AF.

Recent studies confirmed that catecholamine and $\beta 3$-ARs could active MAPK signal pathway, which was a classical pathway in many tissues or organs including heart [7]. It was reported that a highly selective $\beta 3$-ARs agonist in rodents can increase lipids oxidation [6]. The evidence supported that oxidative stress might be induced by activation of $\beta 3$-ARs. Zhang et al [26] exposed cardiomyocytes and fibroblasts from F344 neonatal rat hearts to different concentrations of hydrogen peroxide $\left(\mathrm{H}_{2} \mathrm{O}_{2}\right)$ and menadione (superoxide generator), and found that cardiac myocytes and fibroblasts were both vulnerable to the oxidative damage, which was closely related to MAPK cascade. Oxidative stress might be an important role in mediating $\beta 3$-ARs/p38 MAPK pathway in cardiomyocytes. Similarly, in our study, we found that $\beta 3$-ARs agonist could increase the phosphorylated p38 MAPK, leading to severer oxidative damage, apoptosis and fibrosis in atrium. The antagonist of $\beta 3$-ARs can markedly reverse these effects, lessened the CVF, and ameliorated the atrial function.

It should also be noted that the AF animal models includes rapid atrial pacing, mitral valve regurgitation, congestive heart failure et al. Among them, rapid atrial pacing has been generally used in atrial electrical remodeling studies [27, 28]. On the other hand, it has also been employed in atrial structural remodeling studies $[29,30]$. In addition, experimental results form our previous studies and others have demonstrated that rapid atrial pacing could successfully stimulate the structural changes of the atrium, such as atrial fibrosis. Moreover, the frequency and duration of pacing were not consistent in different studies. Both $400 \mathrm{bpm}$ for 6 weeks and $600 \mathrm{bpm}$ for 3-4 weeks have been reported in previous studies [18, 19]. Therefore, the frequency and duration of pacing should be considered when the extent of atrial remodeling in different studies was compared.

A limitation of the present study is that the possible effects of other subtypes of $\beta$-ARs should not be overlook although specific agonist and antagonist of $\beta 3$-ARs were employed. Currently, BRL37344 and L748337 were widely used as the specific agonist and antagonist for $\beta 3$-ARs, which mainly binding to $\beta 3$-ARs and have low affinities with $\beta 1-/ \beta 2$-AR. More conclusive data are required to further explore the relationship between $\beta 3$-ARs and atrial structural remodeling of AF.

\section{Acknowledgements}

This work was supported by the Program for New Century Excellent Talents in University (No. NCET-09-0132), National Natural Science Foundation of China (30871063, 30971251 and 81070160), Heilongjiang Education Health Department (11551254), Science Key Foundation of Heilongjiang Province (GB07C32401), Technology Plan Project of Heilongjiang province (GC09C408-2), Key Science and Technology Program of Harbin City (2007AA3CS082) and Scientific and Technical Research Major Project of Education Department (211047).

\section{References}

1 Wakili R, Voigt N, Kääb S, Dobrev D, Nattel S: Recent advances in the molecular pathophysiology of atrial fibrillation. J Clin Invest 2011;121:2955-2968.

2 Allessie M, Ausma J, Schotten U: Electrical, contractile and structural remodeling during atrial fibrillation. Cardiovasc Res 2002;54:230-246.

3 Mathew ST, Patel J, Joseph S: Atrial fibrillation: Mechanistic insights and treatment options. European Journal of Internal Medicine 2009;20:672-681.

4 Li Y, Sheng L, Li W, Liu W, Gong Y, Xue H, Shan H: Probucol attenuates atrial structural remodeling in prolonged pacing-induced atrial fibrillation in dogs. Biochem Biophys Res Commun 2009;381:198-203.

5 Brodde OE, Bruck H, Leineweber K: Cardiac adrenoceptors: physiological and pathophysiological relevance. J Pharmacol Sci. 2006;100:323-337. 


\section{Cellular Physiology and Biochemistry \\ Cell Physiol Biochem 2012;30:372-381 \\ \begin{tabular}{l|l}
\hline DOI: 10.1159/000339031 & C 2012 S. Karger AG, Basel
\end{tabular} \\ www.karger.com/cpb \\ Sheng/Shen/Huang et al.: Role of $\beta 3$-ARs in Atrial Structural Remodeling}

6 Coman OA, Paunescu H, Ghita I, Coman L, Badararu A, Fulga I: Beta 3 adrenergic receptors: molecular, histological, functional and pharmacological approaches. Rom J Morphol Embryol 2009;50:169-179.

7 Ursino MG, Vasina V, Raschi E, Crema F, De Ponti F: The beta3-adrenoceptor as a therapeutic target: current perspectives. Pharmacol Res 2009;59:221-234.

8 Morimoto A, Hasegawa H, Cheng HJ, Little WC, Cheng CP: Endogenous beta3- adrenoreceptor activation contributes to left ventricular and cardiomyocyte dysfunction in heart failure. Am J Physiol Heart Circ Physiol 2004;286: H2425-H2433.

9 Cheng HJ, Zhang ZS, Onishi K, Ukai T, Sane DC, Cheng CP: Upregulation of functional beta(3)-adrenergic receptor in the failing canine myocardium. Circ Res 2001;89:599-606.

10 Zhou S, Tan AY, Paz O, Ogawa M, Chou CC, Hayashi H, Nihei M, Fishbein MC, Chen LS, Lin SF, Chen PS: Antiarrhythmic effects of beta3-adrenergic receptor stimulation in a canine model of ventricular tachycardia. Heart Rhythm 2008;5:289-297.

11 Moniotte S, Kobzik L, Feron O, Trochu JN, Gauthier C, Balligand JL: Upregulation of beta(3)-adrenoceptors and altered contractile response to inotropic amines in human failing myocardium. Circulation 2001;103:1649-1655.

12 Brixius K, Bloch W, Pott C, Napp A, Krahwinkel A, Ziskoven C, Koriller M, Mehlhorn U, Hescheler J, Fleischmann B, Schwinger RH: Mechanisms of beta 3-adrenoceptor-induced eNOS activation in right atrial and left ventricular human myocardium. Br J Pharmacol 2004;143:1014-1022.

13 Mihm MJ, Yu F, Carnes CA, Reiser PJ, McCarthy PM, Van Wagoner DR, Bauer JA: Impaired myofibrillar energetics and oxidative injury during human atrial fibrillation. Circulation 2001;104:174-180.

14 Dudley SC Jr, Hoch NE, McCann LA, Honeycutt C, Diamandopoulos L, Fukai T, Harrison DG, Dikalov SI, Langberg J: Atrial fibrillation increases production of superoxide by the left atrium and left atrial appendage: role of the NADPH and xanthine oxidases. Circulation 2005;112:1266-1273.

15 Reilly SN, Jayaram R, Nahar K, Antoniades C, Verheule S, Channon KM, Alp NJ, Schotten U, Casadei B: Atrial sources of reactive oxygen species vary with the duration and substrate of atrial fibrillation. Circulation 2011;124:1107-1117.

16 Goette A, Staack T, Röcken C, Arndt M, Geller JC, Huth C, Ansorge S, Klein HU, Lendeckel U: Increased expression of extracellular signal-regulated kinase and angiotensin-converting enzyme in human atria during atrial fibrillation. J Am Coll Cardiol 2000;35:1669-1677.

17 Lin CS, Pan CH: Regulatory mechanisms of atrial fibrotic remodeling in atrial fibrillation. Cell Mol Life Sci 2008;65:1489-1508.

18 Li Y, Li WM, Gong YT, Li BX, Liu W, Han W, Dong D, Sheng L, Xue JY, Zhang L, Chu S, Yang BF: The effects of cilazapril and valsartan on the mRNA and protein expressions of atrial calpains and atrial structural remodeling in atrial fibrillation dogs. Basic Res Cardiol 2007;102:245-256.

19 Lin CS, Lai LP, Lin JL, Sun YL, Hsu CW, Chen CL, Mao SJ, Huang SK: Increased expression of extracellular matrix proteins in rapid atrial pacing-induced atrial fibrillation. Heart Rhythm 2007;4:938-949.

20 Zhao J, Li J, Li W, Li Y, Shan H, Gong Y, Yang B: Effects of spironolactone on atrial structural remodelling in a canine model of atrial fibrillation produced by prolonged atrial pacing. British Journal of Pharmacology 2010;159:1584-1594.

21 Kim YM, Guzik TJ, Zhang YH, Zhang MH, Kattach H, Ratnatunga C, Pillai R, Channon KM, Casadei B: A myocardial Nox2 containing NAD(P)H oxidase contributes to oxidative stress in human atrial fibrillation. Circ Res 2005;97:629-636.

22 Son Y, Cheong YK, Kim NH, Chung HT, Kang DG, Pae HO: Mitogen-activated protein kinases and reactive oxygen species: How can ROS activate MAPK pathways. J Signal Transduct 2011;2011:792639.

23 Liu GY, Hung YC, Hsu PC, Liao YF, Chang WH, Tsay GJ, Hung HC: Ornithine decarboxylase prevents tumor necrosis factor alpha-induced apoptosis by decreasing intracellular reactive oxygen species. Apoptosis 2005;10:569-581.

24 Thuc LC, Teshima Y, Takahashi N, Nagano-Torigoe Y, Ezaki K, Yufu K, Nakagawa M, Hara M, Saikawa T: Mitochondrial K(ATP) channels- derived reactive oxygen species activate pro-survival pathway in pravastatin- induced cardioprotection. Apoptosis 2010;15:669-678.

25 Yu J, Li W, Li Y, Zhao J, Wang L, Dong D, Pan Z, Yang B: Activation of beta(3)-adrenoceptor promotes rapid pacing-induced atrial electrical remodeling in rabbits. Cell Physiol Biochem 2011;28:87-96.

26 Zhang X, Azhar G, Nagano K, Wei JY: Differential vulnerability to oxidative stress in rat cardiac myocytes versus fibroblasts. J Am Coll Cardiol 2001;38: 2055-2062.

27 Nakashima H, Kumagai K: Reverse-remodeling effects of angiotensin II type 1 receptor blocker in a canine atrial fibrillation model. Circ J 2007;71:1977-1982.

28 Shiroshita-Takeshita A, Sakabe M, Haugan K, Hennan JK, Nattel S: Model-dependent effects of the gap junction conduction-Enhancing antiarrhythmic peptide rotigaptide (ZP123) on experimental atrial fibrillation in dogs. Circulation. 2007;115:310-318.

29 Kinebuchi O, Mitamura H, Shiroshita-Takeshita A, Kurita Y, Ieda M, Ohashi N, Fukuda Y, Sato T, Miyoshi S, Hara M, Takatsuki S, Nagumo M, Ogawa S: Oral Verapamil attenuates the progression of pacing-induced electrical and mechanical remodeling of the atrium. Circ J 2004;68:494-500.

30 Pan CH, Lin JL, Lai LP, Chen CL, Stephen Huang SK, Lin CS: Downregulation of angiotensin converting enzyme II is associated with pacing-induced sustained atrial fibrillation. FEBS Letters 2007;581:526-534. 